\title{
Effect of Concentrated Growth Factors on alveolar ridge preservation
}

IMPLANT THERAPY OUTCOMES; SURGICAL ASPECTS
Feifei Ma, Ye lin, Feng Sun

Peking University School and Hospital of Stomatology

\section{Abstract}

This study compared CGF treatment of extraction sockets with blank control, and that the use of CGF accelerate socket wound healing after tooth extraction as noticed by increased soft-tissue healing and reduced alveolar bone width resorption using clinical and radiographic methods. Further research is under way.

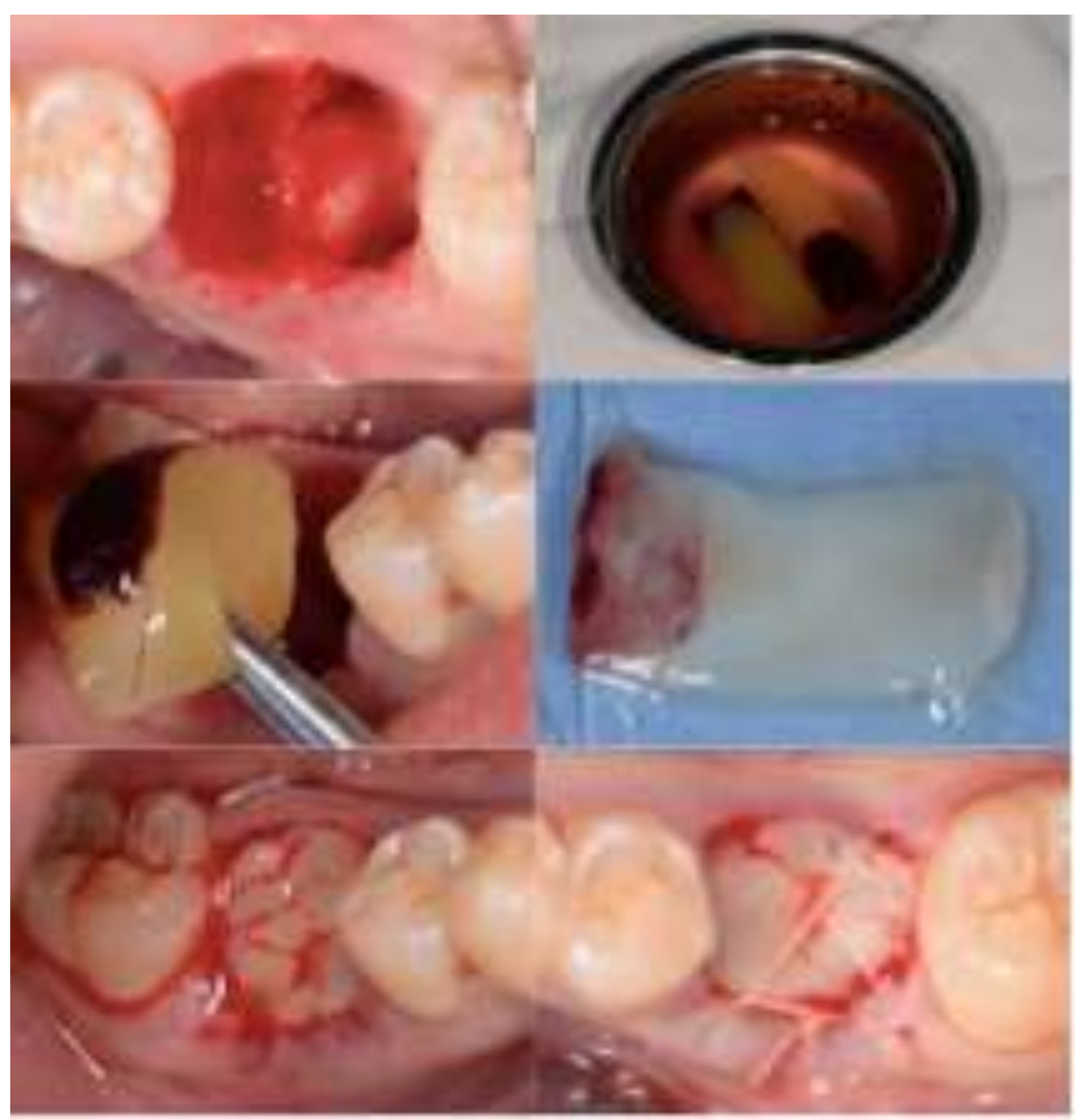

Soft tiusse healing is much faster than the contral group. No significant differences in vertical bone changes in the medium region of the sockets were found $(P>.05)$. Ridge width change is significant differences between the two groups, and the resorption of test group is less than the control group .

\section{Results}

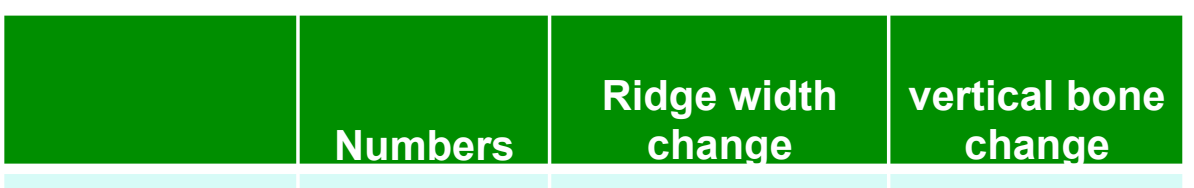

\begin{tabular}{c|c|c|c|}
\hline Control group & 8 & $-1.6 \pm 1.27$ & $-0.22 \pm 1.36$ \\
\hline Test group & 12 & $-0.14 \pm 0.48$ & $-0.18 \pm 0.77$ \\
\hline$P$ 值 & & 0.037 & 0.934 \\
\hline
\end{tabular}

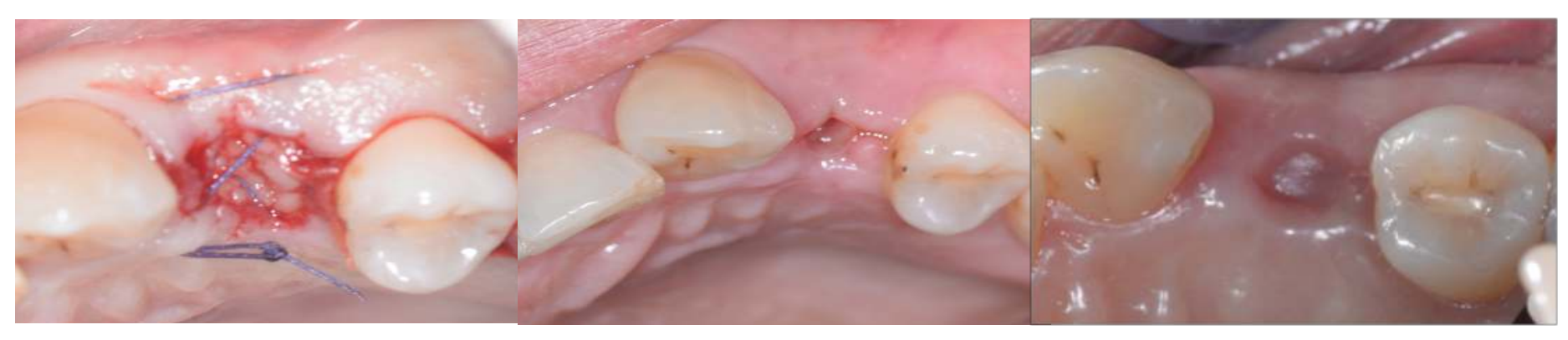

10 days after extraction

1 month after extraction
Background and Aim

Concentrated growth factors(CGF), a third generateon of platelet concenctrate products, appears to have more abundant growth facors because of its special centrifugation processs. It is hypothesized that CGF will accelerate socket wound healing after tooth extraction, noticed by increased bone fill and reduced bone resorption. However,there are few studies supporting this.

This study was designed to evaluate the effect of CGFs in alveolar ridge preservation.

\section{Conclusion}

The study outcomes demonstrate that the use of CGF accelerate socket wound healing after tooth extraction as noticed by increased soft-tissue healing and reduced alveolar bone width resorption using clinical and radiographic methods. Further research is under way.

\section{Methods and Materials}

Twenty subjects needing molar tooth extractions were selected. Twenty extraction sockets were divided into test group (CGF Filled, $n=12$ ) and control group (nature healing, $n=12$ ). The soft tissue profile was evaluated before tooth extraction and after 10-day, 1-month,and 3-month healing. Cone-beam computed tomography scans were taken before extration and 3 months after extraction. Vertical and horizontal bone changes were assessed radiographically. Data were analyzed with Mann- Whitney $\mathrm{U}$ test and $\mathrm{a}=0.05$.

\section{References}

Tan WL, Wong TLT, Wong MCM et al. A systematic review of postextractional alveolar hard and soft tissue dimensional changes in Elisa Borsani, Veronica Bonazza et al. Biological Characterization and In Vitro Effects of Human Concentrated Growth Factor Chan HL, Lin GH, Fu JH et al. Alterations in Bone Quality After Socket Preservation with Grafting Materials: A Systematic Review [J]. Sclar AG. Strategies for management of singletooth extraction sites in aesthetic implant therapy[J]. Journal of Oral and Maxillofacial Surgery,2004,62(9): $90-105$
Jung RE, Siegenthaler DW, Hammerle CHF. Postextraction tissue management: A soft tissue punch technique[J]. International Journal f Periodontics \& Restorative Dentistry, 2004,24(6): 545 Masse JF, Landry RG, Rochette C, et al Efficacy of Plasma-Rich Growth Factor in the Healing of Postextraction Sockets in Patients

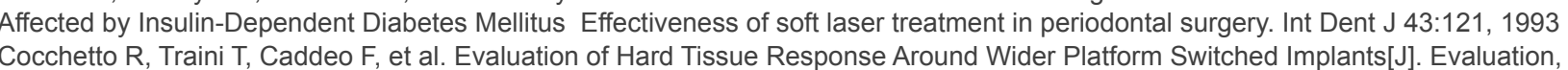
2010,30(2).

$341-363$

Roselló-Camps À, Monje A, Lin GH, Khoshkm V Chávez-Gatty M. Wang HL, Gargall-Albiol J. Hernandez-Alfaro F. Platelet-rich plasma for periodontal regeneration in the treatment of intrabony defects: a meta-analysis on prospective clinical trials. Oral Surg Ora 